\title{
Cultivating learning and fostering flexibility in international distribution
}

\author{
Rudolf R. Sinkovics・Anthony S. Roath
}

\section{This is a pre-print (non-publisher's document). Please cite the published article:}

Sinkovics, Rudolf R. and Anthony S. Roath (2012), "Cultivating learning and fostering flexibility in international distribution," der markt - International journal of marketing, 51 (1), 3-12. (DOI: 10.1007/s12642-011-0067-6). Available:

http://www.manchester.ac.uk/escholar/uk-ac-man-scw:156495

\section{Abstract and Key Results}

- Research examining the relationship among learning orientation, strategic flexibility, and performance is assessed in an international setting focused on exporting manufacturers involved in contractual relationships with foreign distributors.

- Adopting a learning orientation - developing skills in creating, acquiring, and transferring knowledge - has generally been believed to significantly impact performance. In the current research, however, the relationship between learning orientation and performance was not direct, but found to flow indirectly through strategic flexibility.

- The results suggest that learning orientation develops a set of firm capabilities, such as flexibility, that eventually lead to enhanced performance.

\section{Key Words}

- Learning orientation

- Strategic flexibility

- International distribution

\section{Authors}

Rudolf R. Sinkovics ( $\square)$

Professor of International Business

Comparative \& International Business Group, Manchester Business School

The University of Manchester, Manchester, UK.

(e-mail: Rudolf.Sinkovics@manchester.ac.uk, Web:

http://www.personal.mbs.ac.uk/rsinkovics )

Anthony S. Roath

Senior Lecturer in International Business

University of Bath Management School, UK.

(e-mail: A.S.Roath@bath.ac.uk) 


\title{
Cultivating learning and fostering flexibility in international distribution
}

\begin{abstract}
Research examining the relationship among learning orientation, strategic flexibility, and performance is assessed in an international setting focused on exporting manufacturers involved in contractual relationships with foreign distributors. Adopting a learning orientation - developing skills in creating, acquiring, and transferring knowledge - has generally been believed to significantly impact performance. In the current research, however, the relationship between learning orientation and performance was not direct, but found to flow indirectly through strategic flexibility. The results suggest that learning orientation develops a set of firm capabilities, such as flexibility, that eventually lead to enhanced performance.
\end{abstract}

Keywords: learning orientation; strategic flexibility; international distribution 


\section{Cultivating learning and fostering flexibility in international distribution}

\section{$1 \quad$ Introduction}

The success of international supply chains depends, in part, on the ability of supply chain partners to adapt to uncertainties that arise when serving customers in a global environment. The international supply chain is a complex, dynamic system subject to particular "shocks" or disruptions. The increased geographic and psychic distance associated with international supply chains can impact the management of operations in various ways. Disruptions due to demand fluctuations, production disruptions from inefficient host country operations, and transportation and inventory problems can reverberate throughout the supply chain. In addition, managers may make less than optimal decisions based upon their interpretation of these disruptions. International supply-chain managers are also subject to language and cultural differences that further disrupt the flow of communication, reduce flexibility to react and impede performance outcomes (see e.g. Sánchez and Pérez 2005; Vickery, Calantone, and Droge 1999). Within a "typical" short-distance supply chain, these disruptions can be dealt with more easily as the communication is relatively faster and the supply chain is able to react quickly. However, as the supply chain lengthens, the communication becomes less efficient and the supply chain takes longer to react as increased lead time and lead time variability are encountered (Levy 1995).

The uncertainties encountered in international supply chains often force firms to utilize multiple operational configurations to create value tailored to specific customer needs. The requirement to offer differentiated value configurations for distinct geographically and culturally dispersed customers increases the importance of creating internal environments that stress learning as a means to achieve competitive advantages in the global economy (Hult 1998). Firms that have developed internal learning environments can become skilled at outperforming competition and responding to markets faster more efficiently as they pursue new capabilities (Hult 1998). Learning orientation deals with the fundamental significance that an organization assigns to market sensing and dissemination of market information throughout the organization and supply chain. Firms that embrace the concept of learning orientation cultivate an environment in which knowledge is actively created and used (Sinkula, Baker, and Noordewier 1997). Such 
firms develop skills to create, acquire, and transfer knowledge so that they can improve understanding of their environment over time. Management teams that stress organizational learning subsequently modify organizational behavior to reflect new knowledge and insights (Garvin 1993).

Learning oriented firms "recognize and respond to early signals of change or unanticipated opportunities" (Drew and Smith 1998, p.667). Adopting a learning orientation can help firms to improve strategic capabilities including increased flexibility (Drew and Smith 1998). Both learning orientation (Farrell 2000) and flexibility (Michigan State University Global Logistics Research Team 1995; Miles and Snow 1978) have been linked directly to improved performance. Those relationships are explored in the current research within an international supply chain setting, specifically in the context of contractual relationships between U.S. manufacturers and their distributors operating in other countries. As stated earlier, the general research proposition is that an emphasis on learning and subsequent development of strategic flexibility as a result of a firm's intent to apply learning becomes even more critical when operating in an international market.

In the next sections, a brief review of relevant literature is presented and used to support the development of research hypotheses. This is followed by details of the research design, analysis, and results. The paper applies the conceptual and empirical work of Sinkula, Baker, and Noordewier (1997) to organizational learning in an international channel context.

\section{Learning Orientation and Strategic Flexibility}

Two topics are of primary interest in the current research: learning orientation and strategic flexibility. Learning orientation represents the organizational values the firm fosters towards learning. Strategic flexibility highlights one of the organization's ensuing actions as an answer to the organization's desire to develop responsiveness to environmental dynamics. Sinkula, Baker, and Noordewier (1997) describe this concept as market processing behavior - 'responsiveness' that reflects market-based organizational actions (Kohli and Jaworski 1990). Finally, this paper reviews organizational actions as the result of learning orientation's influence on strategic flexibility. 


\subsection{Learning Orientation}

Learning occurs when individuals within organizations respond to changes in their perceived internal and external environments (Sinkula, Baker, and Noordewier 1997). In the process of interacting internally and externally, management teams may "change their shared mental models of their company, their markets, and the competitors" (De Geus 1988, p.70). Simply stated, they use knowledge gained to make changes, solve problems, and take new approaches. Organizational learning is often characterized as a three-stage process: information acquisition, information dissemination, and shared interpretation (Sinkula 1994; Slater and Narver 1995). Others include a fourth stage - organizational memory (Huber 1991).

Information may be acquired from direct experience, experiences of others, or organizational memory (Levitt and March 1988). Thus, information is acquired from internal experiences or external sources which can include benchmarking, joint ventures, networking, alliances, customers, or more formalized methods such as education and training programs (Huber 1991). Information dissemination involves the sharing of information. The value of information may increase as it is shared or passed on to other individuals within the organization. However, this requires the appropriate use of information in a goal-directed manner. Information which is simply accumulated but not exploited suitably, will not contribute to increased economic outcomes. Many organizations have set up task forces or cross-functional teams to facilitate exchange of information across organizations. Finally, each party in the relationship must interpret information in a similar manner. Shared interpretation or a consensus of meaning is necessary.

Organizations which successfully establish learning orientation processes enhance their potential for long-term performance benefits by utilizing the lessons learned from past experiences to guide future actions and responses to the environment (Nevis, DiBella, and Gould 1995; Slater and Narver 1995). Strategic flexibility is one organizational outcome of learning orientation. Sinkula, Baker, and Noordewier (1997) describe this concept as 'responsiveness' that reflects market-based organizational actions (Kohli and Jaworski 1990). Basically, an organization that learns about the ways in which its environment changes is one that is better able to adapt. Organizations that are efficient at learning are likely to be more attentive to their 
markets, can anticipate variations, and are better able to change their market strategies more rapidly. In the context of international supply-chains, diverse cultural and political country environments will prompt learning-oriented firms to engage further in formal market research and exploration activities, which enables them to find new solutions or even solutions for problems which were not necessarily searched for (Day 1994; Hohenthal, Johanson, and Johanson 2003). Hence, they have a higher degree of strategic flexibility or, following the Sinkula, Baker, and Noordewier (1997) framework, high processing behaviors. Situations may arise where higher levels of learning lead firms to suffer from the 'competency trap' (Levitt and March 1988). However, we concur with the broad perspective in the literature that learning, especially learning in and about the international supply-chain, facilitates behavioral changes that lead to improved performance (Fiol and Lyles 1985; Garvin 1993; Senge 1990). It has also been argued that the ability of an organization to learn faster or more adeptly than competitors may be the only source of sustainable competitive advantage (De Geus 1988; Dickson 1992). Therefore, organizations should aim to become learning oriented if they are to compete successfully in the long run (Slater and Narver 1995).

\subsection{Strategic Flexibility}

Strategic flexibility is considered one of the most important attributes firms need in order to operate effectively in the new competitive environment (Hitt, Keats, and DeMarie 1998). Strategic flexibility provides firms with the ability to respond promptly to market opportunities and changing technologies (Sanchez 1995). It represents "an organization's various abilities to respond effectively to a changing competitive environment" (Sanchez 1997, p.72). The characteristics of a strategically flexible organization suggest that the organization has developed an awareness about its environment that enables it to react or anticipate changes competently. Hence, the foundation of strategic flexibility hinges upon an organization's commitment to create an environment conducive to learning in order to acquire and disseminate knowledge.

Some scholars have argued that strategic flexibility represents a polymorphous construct whose exact meaning and conceptualization varies from one context to another (Evans 1991; Young-Ybarra and Wiersma 1999). For example, strategic flexibility can be manifested through a firm's ability to redeploy assets to take advantage of market opportunities and/or avoid problems 
(Grewal and Tansuhaj 2001). Other examples of strategic flexibility include the firm's capacity to make contractual adjustments based upon changing circumstances regarding buyer/seller relationships and the ability to customize service for key customers that have modified their requirements. Accommodations can be made to take advantage of unexpected situations, to keep customers happy, etc. Successful efforts to develop strategic flexibility have been shown to enhance firm performance (Evans 1991; Miles and Snow 1978).

Yet, this paper argues that strategic flexibility can only be an effective capability if the organization has adopted a learning orientation or a culture that stresses and emphasizes the importance of "sensing" and analyzing the market in order to disseminate market awareness and knowledge throughout the organization (Day 1994). These processes and activities contribute to the foundation of the strategic flexibility capability which, in turn, helps to enhance firm performance. Learning orientation suggests that the firm adopts a continuous activity of market assessment that increases its speed and direction of market responsiveness. Learning orientation is a necessary factor of strategic flexibility because it implies that the firm 'learns' to respond positively or rather, in its best interests, when dealing with the global environment.

\section{Conceptual model and research hypotheses}

The research model, presented in Figure 1, explores the interrelationships among learning orientation, strategic flexibility, and performance in manufacturer-distributor relationships.

\subsection{Direct Effect of Learning Orientation on Performance}

A learning orientation creates an environment that encourages open-minded interpretation and questioning of organizational actions (Garvin 1993; Sinkula 1994). It also encourages organizations to challenge perceptions of the environment and to look for better ways to conduct standard business (Argyris and Schön 1978; Bettis and Prahalad 1995). The knowledge derived from a learning orientation helps firms to manage change (Miller and Shamsie 1996). Past research documenting the relationship between learning orientation and performance provides strong support for the notion that those environments fostering improved internal knowledge experience increased performance (Baker and Sinkula 1999; Farrell 2000; Lukas, Hult, and Ferrell 1996; Nevis, DiBella, and Gould 1995). Thus: 
H1: Emphasis on learning orientation is positively related to the organization's performance relative to its competition.

\subsection{Learning Orientation and Strategic Flexibility}

Knowledge generated from learning orientation processes contribute to development of core competencies that enhance competitive advantage (Helleloid and Simonin 1994). Strategic flexibility is one such competency to which learning orientation has been linked (Sanchez 1997). Strategic flexibility enables organizations to apply multiple/varied responses to changes in the environment to achieve objectives while lowering opportunity costs in rapidly changing environments (Hitt, Hoskisson, and Harrison 1991; Phillips and Tuladhar 2000; Sanchez 1995). This perspective suggests a positive relationship between learning orientation and strategic flexibility. In opposition to this notion, Levitt and March (1988) point out that firms may suffer from 'competency trap', thereby inducing strategic inflexibility. Their reasoning is grounded in the notion that learning in principle favors exploitation behavior, whereby search and practice become focused on well-known alternatives. Hence, the benefits of unknown and potentially superior procedures and processes are not actively pursued or acknowledged. Firms are 'lockedin' to familiar actions and decisions; as a result, they become less flexible in adapting to changes in environments. Firms captured in such learning traps need to 'unlearn', in order to enhance strategic flexibility (Hedberg 1981).

The supply-chain context of this study implies a business environment within which manufacturers and their international distributors interact dynamically and competitively. Grant (1996) argues that in such turbulent external business environments learning and the capability to integrate knowledge is of primal importance to achieving superior competitive advantage. Johanson and Vahlne (1977) develop a seminal process model of firm internationalization which points out that firms acquire information about unfamiliar environments gradually. Through the increased awareness of the contingencies associated with foreign markets, they begin to integrate and use this knowledge appropriately. Consequently, organizations demonstrate higher commitment to the markets and less susceptibility to market risks. Hohenthal, Johanson and Johanson (2003) argue that firms expanding internationally perform higher levels of exploration (i.e. search and improvisation) activities. Because of their familiarity with environmental nuances, 
the will have increased their opportunities to deal with unanticipated opportunities, which contributes to becoming more flexible. Building upon this conceptual logic, we argue that a firm's dedicated approach to instilling a culture of learning orientation will facilitate specific forms of 'coordinated self-organizing processes' (Sanchez and Mahoney 1996, p.63) that ultimately will lead to adaptive and strategic responses to accommodate for changing competitive environments (Sanchez 1997). These responses form the essence of positive responsiveness to dynamic markets_-basically, improving a firm's level of strategic flexibility.

\section{H2: $\quad$ Learning orientation is positively related to strategic flexibility.}

\subsection{Strategic Flexibility and Performance}

In situations where organizational tasks are routine or the environment is stable limited information processing and minimal interaction between partners is necessary (Tushman and Nadler 1977). Under these circumstances a task can be effectively completed by means of a structure that is largely hierarchical, composed of standard operating procedures and formal information system. These mechanistic or bureaucratic systems are tailored to enhancing operational efficiencies in day-to-day operations, and advantageous to reducing costs (Burns and Stalker 1961). However, when the external environment is unstable or the nature of exchange is non-routine, as is arguably the case in our international supply chain context, the level of uncertainty increases. Then, firms are better off adopting a fundamentally organic exchange, characterized by decentralized structures and lateral communication. This will render the firm more flexible in dealing with environmental contingencies and more effective in dealing with unforeseen conditions.

We thus argue that strategic flexibility helps keep a firm competitive. Developing the capability to be flexible allows a firm to take advantage of opportunities and avoid problem situations (Grewal and Tansuhaj 2001). Firms with greater strategic flexibility quickly adjust to changing competitive conditions because they can assess the situation and implement decisions under conditions of uncertainty. They develop a capacity to change (Ulrich and Wiersema 1989). Following the deliberations above we argue that strategic flexibility leads to enhanced firm performance (Evans 1991; Miles and Snow 1978): 
H3: $\quad$ Strategic flexibility is positively related to the organization's performance relative to its competition.

In summary, this paper proposes that a firm that creates a learning environment must be willing and able to exploit it to obtain high performance. March (1991) suggests that firms employing an exploitative learning approach tend to achieve more stable economic outcomes than those conducting explorative learning. Subsequently, the firm's learning orientation is a way to create dynamic capabilities such as strategic flexibility. The capability must not only be developed, it must be employed effectively (Barney 1991; Wernerfelt 1984). Therefore, strategic flexibility, as a firm capability, must be leveraged to increase performance.

The following section describes the population, sampling and data collection methods, and analysis techniques used to assess the reliability and validity of the sample data and measurement model.

\section{$4 \quad$ Methodology}

Preliminary interviews with manufacturing firm managers familiar with export operations were conducted to frame the research project. Typically, these managers were tasked with the responsibility for understanding the export market, managing distributor relationships, and monitoring distributor performance. The interviews confirmed that these managers were the appropriate contacts and possessed the knowledge needed to contribute to the current research. Their input provided insight into what they face when working with foreign distributors.

Subsequent to the interviews, data were collected from a sample of exporting manufacturers involved in contractual relationships with foreign distributors. The respondents were identified from a database of domestic export manufacturers obtained through a commercial vendor. Therefore, the sampling frame is composed of medium to high-level managers that are most familiar with the conditions and terms of the contract with their foreign distributor. A relationship was identified as one in which the manufacturer and distributor worked together continuously, potentially even experienced some conflicts or differences but not significant enough to warrant intervention, instruction, or 'extra' monitoring. The interviews and pretests suggested that this type of relationship in an international context was most typical. 
Since small companies are less likely to have the resources for well-developed international distribution functions, companies with fewer than 50 employees were excluded from the research. Eight hundred firms were randomly selected from the remaining sample frame and a questionnaire containing the research variables was mailed to each. A second mailing was sent to all firms three weeks later. This mailing was followed with telephone contact requesting response. A total of 162 surveys were returned. Twenty-one were incomplete, resulting in 141 responses suitable for analysis for an effective response rate of $19.1 \%$.

The responding firms represented a comprehensive cross-section of product technology, thus minimizing industry-specific bias and enhancing the generalizability of the results. The industries represented include machine tools and equipment, industrial tools, appliances, medical equipment, electronic equipment, furniture, chemicals, and telecommunications. The manufacturers had established relationships with many different countries ranging from developing to industrialized nations. The range of companies enriched the value of the data because the various relationships reflect different types of relationship profiles. A table of respondent characteristics is illustrated in Table 1. A test for nonresponse bias was completed following the Armstrong and Overton (1977) procedure to detect differences in means between early and late respondents. Based on the analysis, no significant differences were found between the sample groups on the variables of interest.

Insert Table 1 approximately here

\subsection{Measure reliability and validity}

Measures for the constructs were identified in the literature, modified and refined based on information gained during the interviews. Another group of managers reexamined the modified scales for face and content validity. Subsequently, a survey instrument was developed and administered to a sample pretest of 35 respondents prior to final modification. These steps led to the final survey instrument. 
The learning orientation measures are adapted from Sinkula (1994). Strategic flexibility measures are from Lusch and Brown (1996), which are based on Heide and John (1992). The performance measures are from Cavusgil and Zou (1994) and reflect overall performance in the foreign market. All items are measured on 7-point Likert scales $(1=$ strongly disagree and $7=$ strongly agree). The respondents were asked to reflect upon a foreign distributor with whom the company had frequent contact. This request helped to increase the potential that the managers were more familiar with operations associated with these trade partners. Measures and their coefficient alphas are summarized in Table 2. The high levels for coefficient alphas for each scale help to confirm the reliability of the scales.

Insert Table 2 approximately here

Measurement validity was assessed by confirmatory factor analysis (CFA) following Anderson and Gerbing (1988). CFA provides for a thorough examination of a latent variable model's convergent and discriminant validity. Table 3 reports the results of this analysis.

Insert Table 3 approximately here

The primary outputs of CFA are the assessments of measurement model fit. The traditional chi-square fit test indicates how well the model-implied covariance matrix matches the covariances among the measured variables in the sample data (Bollen 1989; Hayduk 1989; Marsh, Balla, and McDonald 1988). In a reversal of the typical testing assumption, support for the null hypothesis of equal covariances is sought to demonstrate sound model fit. In this case, the chi-square statistic of $46.648(25 \mathrm{df})$ results in a p-value of 0.005 , indicating poor model fit. Chisquare, however, is not the sole measure of fit. Other fit statistics have been developed to provide further indication of goodness-of-fit. The Bentler-Bonett Normed Fit Index (BBNFI), Bentler- 
Bonett Nonnormed Fit Index (BBNNFI), and Comparative Fit Index (CFI) all have values greater than the 0.90 cutoff suggested by the literature indicating reasonable fit (Bagozzi and Yi 1988; Fornell and Larcker 1981; Hu and Bentler 1995). Bentler (1990) and Byrne (1996) claim that the CFI is the single most important index since it accounts for sample size - a common bias in index calculations. In addition, root mean square error (RMSR) is acceptable at 0.050 (Hair et al. 1998). The normed chi-square, a measure of parsimonious fit, is the ratio of the chi-square value to degrees of freedom. In this analysis, the normed chi-square for the CFA is approximately 1.87:1. While no consensus regarding an acceptable value for the normed chi-square statistic has been established, ratios varying from 2:1 to 5:1 have been offered as upper thresholds for acceptable fit (Arbuckle 1997).

Anderson (1987) reports that convergent validity is suggested when factor loadings demonstrate that measurement items load significantly on their designated latent variables. The standardized lambda estimates in Table 3 present evidence of this form of construct validity. The lowest value among the estimates is 0.618 (item LO3) and has an associated t-value of $6.830-$ well above the t-critical value of 2.38 at the 0.01 level of significance. Further support of convergent validity is provided by the lack of significant, theory-driven modification indices (e.g., the Wald and Lagrange Multiplier (LM) Tests in EQS).

Discriminant validity is the degree to which conceptually similar constructs are distinct (Dröge and Germain 2000). An assessment of the correlations among the items underlying the latent variables can provide an indication of discriminant validity. One would expect that correlations for items of the same construct are higher than correlations with items from different constructs. Correlation data presented in Table 4 support this contention for learning orientation and performance. Measures for strategic flexibility, however, tended to correlate highly with measures of performance. The measures were retained based upon strong support for nomological validity during the interviews as well as the pretest input. Again, lack of significant, theory-driven Wald and LM modification indices supports construct distinctiveness and retention of the measures. 
Insert Table 4 approximately here

The next section reports the results of the hypothesis testing and more closely examines the interrelationships among learning orientation, learning outcome, strategic flexibility, and performance.

Insert Table 5 approximately here

\section{$5 \quad$ Results and implications}

The research hypotheses were tested simultaneously in a single structural equation model with EQS (Bollen 1989). Results of the full model analysis are provided in Table 5. As with the measurement model, the chi-square fit statistics for the full model are not acceptable $(46.601 ; \mathrm{df}=$ $24 ; \mathrm{p}=0.003)$. All of the additional fit indices, however, demonstrate sound model fit, with the Comparative Fit Index sufficiently exceeding 0.90 and RMSR is acceptable at 0.062 (Hair et al. 1998). Also, the normed chi-square value of $1.94: 1$ is within the stringent 2.0 standard for parsimonious fit per Arbuckle (Arbuckle 1997). Thus, examination of the hypotheses can proceed given an overall sound assessment of model fit. Figure 1 provides a graphical portrayal of the relationships and the results of the hypothesis tests.

Insert Figure 1 approximately here

Hypothesis 1 predicts a positive relationship between learning orientation and performance. A negative and non-significant relationship exists for the direct link between learning orientation and performance, failing to support $\mathrm{H} 1$ (beta $=-0.126, \mathrm{t}=-1.462 / \mathrm{p}=.451$ ). This result is not 
consistent with previous learning orientation performance studies (Baker and Sinkula 1999; Farrell 2000; Lukas, Hult, and Ferrell 1996; Nevis, DiBella, and Gould 1995).

One explanation for this result is that this research reports responses based upon a relationship with a foreign distributor. Having to deal with this type of distributor forces the manufacturer to work more closely with its partner in order to develop capabilities that help the relationship to achieve its goals. In other words, the structural environment is in place, but the complexity and challenge of the manufacturer-distributor relationship may be preventing performance gains. In instances of domestic relationships, for example, learning orientation may more directly influence performance. Additional skills and capabilities related to a learning orientation may be more easily applied than when dealing with foreign distributors.

A positive and significant path estimate was found for $\mathrm{H} 2$, supporting a relationship between learning orientation and strategic flexibility (beta $=0.358, \mathrm{t}=3.253 / \mathrm{p}=.000$ ). Additionally, learning orientation explained nearly $33 \%$ of the variance in strategic flexibility $\left(\mathrm{R}^{2}=0.327\right)$. The strong implication is that learning orientation helps the firm to develop the ability to recognize and react more quickly to different opportunities and challenges in the market environment. Creating an organizational culture of perceiving and disseminating market knowledge is critical when dealing with foreign distributors. This process eventually contributes to a firm's strategic flexibility.

The third hypothesis (H3), strategic flexibility's positive relationship with performance, is strongly supported (beta coefficient $=0.822, \mathrm{t}=6.695 / \mathrm{p}=.000$ ). Strategic flexibility explained 62 $\%$ of the variance in performance $\left(\mathrm{R}^{2}=0.619\right)$. These results suggest that firms with flexibility capabilities will significantly increase their performance. Flexible firms have created an ability to respond more quickly to changes in the environment, enabling them to provide customized solutions and avoid potentially problematic situations.

\section{Implications and conclusion}

The results of the current research support previous findings that depict learning orientation as a significant antecedent of performance. Importantly, however, the current results indicate that the relationship between learning orientation and performance is not direct, as previously 
suggested, but rather flows indirectly through strategic flexibility. This may reflect the nature of relationships examined - those in which foreign distributors are significantly more difficult to work with and challenge the manufacturer's ability to manage the relationship. Such relationships may require extra accommodation - extra market sensitivity, awareness, and deviation from standard procedures. The increased risks associated with operations in foreign environments may drive the need to ensure more effective organizational communication and coordination to mitigate these market risks. The resulting outcome, responsiveness, becomes a critical component of strategic flexibility, which contributes to enhanced overall performance. While these results may appear intuitively appealing, the empirical support highlights the role of capabilities as a result of learning orientation.

Learning orientation emphasizes the creation of an atmosphere that encourages employees to gather and use all aspects of information that are directly relevant to the relationship. This includes information between manufacturing exporters and foreign distributors (e.g. internal cultures, processes and procedures) as well as environmental information about target market customers, competitors, regulations and culture and operational information regarding distribution and transportation structures, pricing and taxation nuances, and sales patterns.

Strategic flexibility in a relationship can impact performance from both an economic and service perspective. Margins may be improved as the relationship becomes more flexible. Inventory stockouts can be avoided or reduced as flexible responses are developed to take advantage of demand swings due to price cuts, competitive product shortfalls, or currency fluctuations/inflation. For example, alternative, faster distribution options can be developed as backup when increased demand is projected or to make up time lost due to production delays. Finally, more flexible decision processes enable managers to understand and react to the different customer service level requirements of different foreign markets. The service implications of developing a learning orientation and subsequently, strategic flexibility, can be as important as the economic implications. Performance can be enhanced in a multitude of ways and have a longterm, positive impact for firms operating in global markets.

The current research findings are similar to those of Sinkula, Baker, and Noordewier (1997), who concluded that organizational values that support learning orientation ultimately contribute 
to organizational outcomes. Such organizational outcomes are enhanced through mechanisms - in the current case strategic flexibility -- designed to implement learning. Hence, the results of this study provide the basis for arguing that a learning orientation definitely is not enough. The implementation mechanism that the flexibility capability represents must be able to leverage learning orientation in order to produce desired learning outcomes, a vital element that contributes to performance.

The results of this research should be considered along with some constraints. The research takes the perspective of manufacturers asked to analyze their relationships with foreign distributors. A future approach may be to study different types of relationships or to examine relationships at different phases to determine if differences exist.

The traditional problem of not examining relationships from dyadic viewpoints is evident. This limits the research because the data do not reflect the cross-organizational interaction of learning orientation and strategic flexibility on performance. The next step could be to address a cross-border relationship by examining the differences between the organizations in their interpretations of learning orientation and strategic flexibility.

\section{$7 \quad \underline{\text { References }}$}

Anderson, James C. (1987), "An Approach for Confirmatory Measurement and Structural Equation Modeling of Organizational Properties," Management Science, 33 (4), 525-541.

Anderson, James C. and David W. Gerbing (1988), "Structural Equation Modeling in Practice: A Review and Recommended Two-Step Approach," Psychological Bulletin, 103 (3), 411-423.

Arbuckle, James L. (1997), Amos Users' Guide, Version 3.6. Chicago: Smallwaters Inc.

Argyris, Chris and Donald A. Schön (1978), Organizational Learning: A Theory of Action Perspective. Reading, Mass.: Addison-Wesley Publishing.

Armstrong, J. Scott and Terry S. Overton (1977), "Estimating Nonresponse Bias in Mail Surveys," Journal of Marketing Research, 14 (3), 396-402.

Bagozzi, Richard P. and Youjae Yi (1988), "On the Evaluation of Structural Equation Models," Journal of the Academy of Marketing Science, 16 (1), 74-94.

Baker, William E. and James M. Sinkula (1999), "The Synergistic Effect of Market Orientation and Learning Orientation on Organizational Performance," Journal of the Academy of Marketing Science, 27 (4), 411-427.

Barney, Jay B. (1991), "Firm Resources and Sustained Competitive Advantage," Journal of Management, 17 (1), 99-121. 
Bentler, Peter M. (1990), "Fit Indexes, Lagrange Multipliers, Constraint Changes and Incomplete Data in Structural Models," Multivariate Behavioral Research, 25 (2), 163-172.

Bettis, Richard A and C K Prahalad (1995), "The Dominant Logic: Retrospective and Extension," Strategic Management Journal, 16 (1), 5-14.

Bollen, Kenneth A. (1989), Structural Equations with Latent Variables. New York, NY: John Wiley \& Sons.

Burns, Tom and G. M. Stalker (1961), The Management of Innovation. London: Tavistock Publications.

Byrne, Barbara M. (1996), Structural Equation Modeling with EQS and EQS-Windows. Thousand Oaks, CA: Sage Publications.

Cavusgil, S. Tamer and Shaoming Zou (1994), "Marketing Strategy-Performance Relationship: An Investigation of the Empirical Link in Export Market Ventures," Journal of Marketing, $58(1), 1-21$.

Day, George S. (1994), "The Capabilities of Market-Driven Organizations," Journal of Marketing, 58 (4), 37-53.

De Geus, Arie P. (1988), "Planning as Learning," Harvard Business Review, 66 (2), 70-74.

Dickson, Peter Reid (1992), "Toward a General Theory of Competitive Rationality," Journal of Marketing, 56 (1), 69-83.

Drew, Stephen A. W. and Peter A. C. Smith (1998), "The New Logistics Management: Transformation through Organizational Learning," International Journal of Physical Distribution \& Logistics Management, 28 (9), 666-681.

Dröge, Cornelia and Richard Germain (2000), "The Relationship of Electronic Data Interchange with Inventory and Financial Performance," Journal of Business Logistics, 21 (2), 209-230.

Evans, J. Stuart (1991), "Strategic Flexibility for High Technology Manoeuvres: A Conceptual Framework," The Journal of Management Studies, 28 (1), 69-89.

Farrell, Mark A. (2000), "Developing a Market-Oriented Learning Organisation," Australian Journal of Management, 25 (2), 201-222.

Fiol, C. Marlene and Marjorie A. Lyles (1985), "Organizational Learning," Academy of Management Review, 10 (4), 803-813.

Fornell, Claes and David F. Larcker (1981), "Evaluating Structural Equation Models with Unobservable Variables and Measurement Error," Journal of Marketing Research, 18 (1), $39-50$.

Garvin, David A. (1993), "Building a Learning Organization," Harvard Business Review, 71 (4), 78-93.

Grant, Robert M. (1996), "Prospering in Dynamically-Competitive Environments: Organizational Capability as Knowledge Integration," Organization Science, 7 (4), 375-387.

Grewal, Rajdeep and Patriya Tansuhaj (2001), "Building Organizational Capabilities for Managing Economic Crisis: The Role of Market Orientation and Strategic Flexibility," Journal of Marketing, 65 (2), 67-80.

Hair, Joseph F., Rolph E. Anderson, Ronald L. Tatham, and William C. Black (1998), Multivariate Data Analysis (5th ed.). Upper Saddle River: Prentice-Hall. 
Hayduk, Leslie A. (1989), Structural Equation Modelling with Lisrel. Baltimore: Johns Hopkins Univ. Press.

Hedberg, Bo L.T. (1981), "How Organizations Learn and Unlearn," in Handbook of Organizational Design, Paul C. Nyström and William H. Starbuck, eds. Vol. 1. Oxford: Oxford University Press.

Heide, Jan B. and George John (1992), "Do Norms Matter in Marketing Relationships?," Journal of Marketing, 56 (2), 32-44.

Helleloid, D. and Bernard L. Simonin (1994), "Organizational Learning and a Firm's Core Competence," in Competence-Based Competition, Gary Hamel and Aimé Heene, eds. Vol. 5. Chichester: Wiley.

Hitt, Michael A., Robert E. Hoskisson, and Jeffrey S. Harrison (1991), "Strategic Competitiveness in the 1990s: Challenges and Opportunities for U.S. Executives," The Academy of Management Executive, 5 (2), 7-22.

Hitt, Michael A., Barbara W. Keats, and Samuel M. DeMarie (1998), "Navigating in the New Competitive Landscape: Building Strategic Flexibility and Competitive Advantage in the 21st Century," The Academy of Management Executive, 12 (4), 22-42.

Hohenthal, Jukka, Jan Johanson, and Martin Johanson (2003), "Market Discovery and the International Expansion of the Firm," International Business Review, 12 (6), 659-672.

$\mathrm{Hu}$, Li-tze and Peter M. Bentler (1995), "Evaluating Model Fit," in Structural Equation Modeling: Concepts, Issues, and Applications, Rick H. Hoyle, ed. Thousand Oaks, CA.: Sage Publications.

Huber, George P. (1991), "Organizational Learning: The Contributing Processes and the Literatures," Organization Science, 2 (1), 88-115.

Hult, G Tomas M (1998), "Managing the International Strategic Sourcing Process as a MarketDriven Organizational Learning System," Decision Sciences, 29 (1), 193-216.

Johanson, Jan and Jan-Erik Vahlne (1977), "The Internationalization Process of the Firm - a Model of Knowledge Development and Increasing Foreign Market Commitments," Journal of International Business Studies, 8 (1), 23-32.

Kohli, Ajay K. and Bernard J. Jaworski (1990), "Market Orientation: The Construct, Research Propositions and Managerial Implications," Journal of Marketing, 54 (2), 1-18.

Levitt, Barbara and James G. March (1988), "Organizational Learning," Annual Review of Sociology, 14, 319-340.

Levy, David L. (1995), "International Sourcing and Supply Chain Stability," Journal of International Business Studies, 26 (2), 343-360.

Lukas, Bryan A., G. Tomas M. Hult, and O. C. Ferrell (1996), "A Theoretical Perspective of the Antecedents and Consequences of Organizational Learning in Marketing Channels," Journal of Business Research, 36 (3), 233-244.

Lusch, Robert F. and James R. Brown (1996), "Interdependency, Contracting, and Relational Behavior in Marketing Channels," Journal of Marketing, 60 (4), 19-38.

March, James G. (1991), "Exploration and Exploitation in Organizational Learning," Organization Science, 2 (1), 71-87.

Marsh, Herbert W., John R. Balla, and Roderick P. McDonald (1988), "Goodness-of-Fit Indexes 
in Confirmatory Factor Analysis: The Effect of Sample Size," Psychological Bulletin, 103 (3), 391.

Michigan State University Global Logistics Research Team (1995), World Class Logistics: The Challenge of Managing Continuous Change. Oak Brook, IL.: Council of Logistics Management.

Miles, Raymond E. and Charles C. Snow (1978), Organizational Strategy, Structure, and Process. New York: McGraw-Hill.

Miller, Danny and Jamal Shamsie (1996), "The Resource-Based View of the Firm in Two Enviroments: The Hollywood Film Studios from 1936 to 1965," Academy of Management Journal, 39 (3), 519-543.

Nevis, Edwin C, Anthony J DiBella, and Janet M Gould (1995), "Understanding Organizations as Learning Systems," Sloan Management Review, 36 (2), 73-85.

Phillips, Fred and Sugandha D. Tuladhar (2000), "Measuring Organizational Flexibility: An Exploration and General Model," Technological Forecasting and Social Change, 64 (1), 23-38.

Sánchez, Angel Martínez and Manuela Pérez Pérez (2005), "Supply Chain Flexibility and Firm Performance: A Conceptual Model and Empirical Study in the Automotive Industry," International Journal of Operations \& Production Management, 25 (7), 681-700.

Sanchez, Ron (1995), "Strategic Flexibility in Product Competition," Strategic Management Journal, 16, 135-159.

---- (1997), "Preparing for an Uncertain Future. Managing Organisations for Strategic Flexibility," International Studies of Management and Organisation, 27 (2), 71-94.

Sanchez, Ron and Joseph T Mahoney (1996), "Modularity, Flexibility, and Knowledge Management in Product and Organization Design," Strategic Management Journal, 17 (Special Issue), 63-76.

Senge, Peter M. (1990), The Fifth Discipline. The Art and Practice of the Learning Organization. New York: Doubleday.

Sinkula, James M. (1994), "Market Information Processing and Organizational Learning," Journal of Marketing, 58 (1), 35-45.

Sinkula, James M., William E. Baker, and Thomas Noordewier (1997), "A Framework for Market-Based Organizational Learning: Linking Values, Knowledge, and Behavior," Journal of the Academy of Marketing Science, 25 (4), 305-318.

Slater, Stanley F. and John C. Narver (1995), "Market Orientation and the Learning Organization," Journal of Marketing, 59 (3), 63-74.

Tushman, Michael L and David A Nadler (1977), "Information Processing as an Integrating Concept in Organizational Design," Academy of Management Review, 3 (3), 613-624.

Ulrich, David and Margarethe F. Wiersema (1989), "Gaining Strategic and Organizational Capability in a Turbul," The Academy of Management Executive, 3 (2), 115-122.

Vickery, Shawnee, Roger Calantone, and Cornelia Droge (1999), "Supply Chain Flexibility: An Empirical Study," Journal of Supply Chain Management, 35 (3), 25-33.

Wernerfelt, Birger (1984), "A Resource-Based View of the Firm," Strategic Management Journal, 5 (2), 171-181. 
Young-Ybarra, Candace and Margarethe Wiersma (1999), "Strategic Flexibility in Information Technology Alliances: The Influence of Transaction Cost Economics and Social Exchange Theory," Organization Science, 10 (4), 439-459.

\section{Appendix}

Figure 1: Conceptual model and hypothesis test results

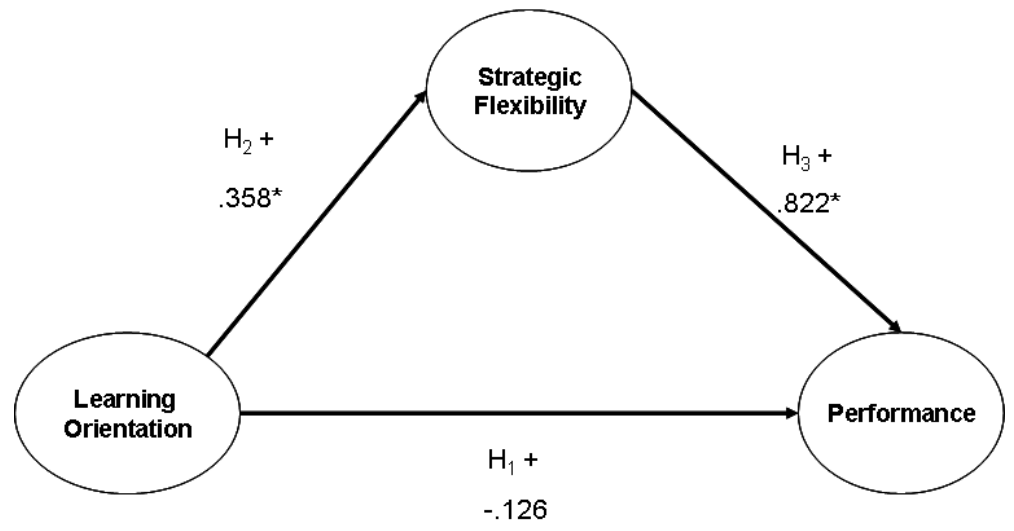

$\begin{array}{ll}\text { Chi-Square }- & 46.601(\mathrm{df}=24, \mathrm{p}=0.005) \\ \text { CFI - } & .963 \\ \text { IFI - } & .963 \\ \text { AGFI - } & .860 \\ \text { RMSR - } & .062\end{array}$


Table 1: Respondent characteristics

\begin{tabular}{|l|l|l|l|l|}
\hline Industry & $\begin{array}{l}\text { Years } \\
\text { Experience } \\
\text { (Avg) }\end{array}$ & $\begin{array}{l}\text { \# of } \\
\text { Export } \\
\text { Personnel }\end{array}$ & $\begin{array}{l}\text { \# of } \\
\text { Distributors }\end{array}$ & $\begin{array}{l}\text { Country/Region of } \\
\text { Distributor ^ }\end{array}$ \\
\hline Household Appliances & 14.3 & 1.6 & 2 & Europe \\
\hline Automotive & 23.4 & $3.6^{*}$ & $9 *^{*}$ & Europe \\
\hline Telecommunication & 14.3 & 4.6 & 31.6 & Middle East/Africa \\
\hline Paper/Publishing & 5.6 & 2.0 & 16.3 & Pac Rim/China \\
\hline Electronic Equip & 22.0 & $3.5 \#$ & 24.6 & Pac Rim/China \\
\hline Pharmaceutical & 26.6 & 3.8 & 5 & Pac Rim/China \\
\hline Med Equipment & 9.3 & 6.0 & 73.3 & Europe \\
\hline Furniture & 28.8 & 3.0 & 14.3 & Pac Rim/China \\
\hline Heavy Machinery & 28.8 & 19.7 & 48.8 & Pac Rim/China \\
\hline Industrial Machinery & 29.1 & 3.2 & 24.1 & Pac Rim/China \\
\hline Chemical & 26.9 & 20.7 & 38.2 & Europe \\
\hline Other & 21.5 & 7.5 & 30.2 & Pac Rim/China \\
\hline
\end{tabular}

This table reports the average per industry category.

* One company has 350 people dedicated to foreign operations

\# This mean does not include 2 companies with more than 100 personnel dedicated to foreign operations

**Two companies have more than 250 distributors

$\wedge$ Respondents reported the region where their "most foreign" distributor was located. This number reflects the highest percentage (concentration) for the particular industry. The Pacific Rim/China area was reported as the region of the most foreign distributor (40\%) by almost all industries. This was followed by Europe (23.7\%) and Mexico/Central America (12.6\%). 
Table 2: Measurement scales

\section{Learning Orientation (LO): coefficient alpha -- 0.8184}

1. We strongly encourage our employees to share fresh ideas with distributors.

2. Our company works with distributors to continually improve capabilities.

3. We encourage our distributors to participate actively in joint training activities.

4. Joint training programs with our distributors are designed to improve mutual learning.

\section{Strategic Flexibility (SF): coefficient alpha -- 0.7958}

1. Both partners are able to make adjustments in the ongoing relationship to cope with changing political, economic, or legal circumstances.

2. Together, we have developed processes to increase flexibility in response to customer requests.

3. We are unable to make adjustments in our relationship to accommodate changing circumstances. (Reverse scaled)

\section{Performance (P): coefficient alpha -- 0.8858}

1. The distributor has helped increase our overall performance in this market.

2. The distributor has helped increase the performance of our core product in this market.

3. The distributor has helped make our company more competitive relative to our competition in terms of profitability. 
Table 3: Confirmatory factor analysis of measurement model

\begin{tabular}{|c|c|c|c|}
\hline & $\begin{array}{c}\text { Learning } \\
\text { Organization }\end{array}$ & $\begin{array}{c}\text { Strategic } \\
\text { Flexibility }\end{array}$ & Performance \\
\hline LO1 & $0.756^{\mathrm{b}}$ & & \\
\hline LO2 & $0.918(7.747)^{\mathrm{a}}$ & & \\
\hline LO3 & $0.780(7.326)$ & & \\
\hline LO4 & $0.618(6.830)$ & & \\
\hline SF1 & & $0.682^{\mathrm{b}}$ & \\
\hline SF2 & & $0.803(7.436)$ & \\
\hline SF3 & & $0.679(6.607)$ & $0.930^{\mathrm{b}}$ \\
\hline P1 & & & $0.936(9.582)$ \\
\hline P2 & & & $0.697(10.334)$ \\
\hline P3 & & & \\
\hline
\end{tabular}

${ }^{a} t$-values in parentheses are from the unstandardized solution

${ }^{b} t$-values for these parameters are not available given that they were fixed for scaling purposes per Byrne (1996).

Fit statistics:

\begin{tabular}{|l|c|}
\hline & CFA \\
\hline Chi-square & $46.648(\mathrm{df}=25, \mathrm{p}=0.005)$ \\
\hline Bentler-Bonett Normed Fit Index (BBNFI) & 0.927 \\
\hline Bentler-Bonett Nonnormed Fit Index (BBNNFI) & 0.948 \\
\hline Comparative Fit Index (CFI) & 0.964 \\
\hline Root Mean Square Residual (RMSR) & 0.050 \\
\hline
\end{tabular}

Maximum Likelihood (ML) solution 
Table 4: Measure correlations

\begin{tabular}{|c|c|c|c|c|c|c|c|c|c|}
\hline & $\mathrm{LO} 1$ & LO2 & LO3 & LO4 & SF1 & SF2 & SF3 & P1 & P2 \\
\hline LO2 & $\begin{array}{c}.694 \\
.000 * *\end{array}$ & & & & & & & & \\
\hline LO3 & $\begin{array}{c}.319 \\
.000 * *\end{array}$ & $\begin{array}{c}.448 \\
.000^{* *}\end{array}$ & & & & & & & \\
\hline LO4 & $\begin{array}{c}.503 \\
.000 * *\end{array}$ & $\begin{array}{c}.601 \\
.000 * *\end{array}$ & $\begin{array}{c}.573 \\
.000^{* *}\end{array}$ & & & & & & \\
\hline SF1 & $\begin{array}{c}.251 \\
.003 * * \\
\end{array}$ & $\begin{array}{c}.221 \\
.010^{*} \\
\end{array}$ & $\begin{array}{l}.166 \\
.053 \\
\end{array}$ & $\begin{array}{c}.290 \\
.001 * * \\
\end{array}$ & & & & & \\
\hline SF2 & $\begin{array}{c}.179 \\
.036^{*}\end{array}$ & $\begin{array}{c}.232 \\
.006 * *\end{array}$ & $\begin{array}{c}.312 \\
.000^{* *}\end{array}$ & $\begin{array}{c}.214 \\
.012 *\end{array}$ & $\begin{array}{c}.236 \\
.005 * *\end{array}$ & & & & \\
\hline SF3 & $\begin{array}{l}.172 \\
.044^{*}\end{array}$ & $\begin{array}{c}.246 \\
.004 * *\end{array}$ & $\begin{array}{c}.305 \\
.000^{* *}\end{array}$ & $\begin{array}{l}.201 \\
.019 *\end{array}$ & $\begin{array}{l}.212 \\
.013^{*}\end{array}$ & $\begin{array}{c}.569 \\
.000 * *\end{array}$ & & & \\
\hline P1 & $\begin{array}{l}.152 \\
.070\end{array}$ & $\begin{array}{l}.138 \\
.103\end{array}$ & $\begin{array}{l}.003 \\
.957\end{array}$ & $\begin{array}{l}.066 \\
.441\end{array}$ & $\begin{array}{c}.467 \\
.000 * *\end{array}$ & $\begin{array}{c}.585 \\
.000^{* *}\end{array}$ & $\begin{array}{c}.372 \\
.000 * *\end{array}$ & & \\
\hline P2 & $\begin{array}{l}.042 \\
.652\end{array}$ & $\begin{array}{l}.064 \\
.447\end{array}$ & $\begin{array}{l}.061 \\
.470\end{array}$ & $\begin{array}{l}.030 \\
.723\end{array}$ & $\begin{array}{c}.442 \\
.000 * *\end{array}$ & $\begin{array}{c}.644 \\
.000 * *\end{array}$ & $\begin{array}{c}.453 \\
.000^{* *}\end{array}$ & $\begin{array}{c}.877 \\
.000 * *\end{array}$ & \\
\hline P3 & $\begin{array}{c}.220 * * \\
.010\end{array}$ & $\begin{array}{l}.159 \\
.063\end{array}$ & $\begin{array}{l}.148 \\
.083\end{array}$ & $\begin{array}{l}.124 \\
.150\end{array}$ & $\begin{array}{c}.426 \\
.000 * *\end{array}$ & $\begin{array}{c}.529 \\
.000 * *\end{array}$ & $\begin{array}{c}.320 \\
.000 * *\end{array}$ & $\begin{array}{c}.686 \\
.000 * *\end{array}$ & $\begin{array}{c}.853 \\
.000^{* *}\end{array}$ \\
\hline
\end{tabular}

* sig at 0.05

** sig at 0.01 
Table 5: Structural model results and assessment of fit

\begin{tabular}{|l|c|c|}
\hline \multicolumn{3}{|c|}{ Structural path estimates } \\
\hline Parameter & $\begin{array}{c}\text { Standardized } \\
\text { estimate }\end{array}$ & t-value $^{\mathrm{a}}$ \\
\hline$\beta 1$ & -0.126 & -1.462 \\
\hline$\beta 3$ & 0.358 & 3.253 \\
\hline \multicolumn{3}{|c|}{ Measurement model estimates } \\
\hline Parameter & $\begin{array}{c}\text { Standardized } \\
\text { estimate }\end{array}$ & t-value \\
\hline LO1,LO & $.756^{\mathrm{b}}$ & --- \\
\hline LO2,LO & .918 & 7.747 \\
\hline LO3,LO & .780 & 7.326 \\
\hline LO4,LO & .618 & 6.830 \\
\hline SF1,SF & $.682^{\mathrm{b}}$ & --- \\
\hline SF2,SF & .803 & 7.436 \\
\hline SF3,SF & .679 & 6.607 \\
\hline P1,P & $.930^{\mathrm{b}}$ & --- \\
\hline P2,P & .936 & 9.582 \\
\hline P3,P & .697 & 10.334 \\
\hline
\end{tabular}

${ }^{a} t$-values are from the unstandardized solution

${ }^{b} t$-values for these parameters were not available because they were fixed for scaling Fit statistics:

\begin{tabular}{|l|c|}
\hline Chi-square: & 46.601 (d.f. $=24, \mathrm{p}=0.003)$ \\
\hline Bentler-Bonett Normed Fit Index (BBNFI) & 0.927 \\
\hline Bentler-Bonett Nonnormed Fit Index (BBNNFI) & 0.944 \\
\hline Comparative Fit Index (CFI) & 0.963 \\
\hline Root Mean Square Residual (RMSR) & 0.062 \\
\hline
\end{tabular}

Maximum Likelihood (ML) solution

R-square values:

\begin{tabular}{|l|l|}
\hline Endogenous variable & R-square \\
\hline SF & 0.327 \\
\hline P & 0.619 \\
\hline
\end{tabular}

